\title{
Inhaled corticosteroid therapy does not control asthma
}

\author{
Robert L Cowie MD, Margot F Underwood BN, Stephen K Field MD
}

RL Cowie, MF Underwood, SK Field. Inhaled corticosteroid therapy does not control asthma. Can Respir J 2004;11(8):555-558.

BACKGROUND: Randomized clinical trials demonstrate efficacy and show that inhaled corticosteroid therapy can control asthma, but details concerning their effectiveness in achieving this goal in the community are lacking.

OBJECTIVES: To determine whether inhaled corticosteroid therapy is effective in controlling asthma and to examine the rates of asthma control in relation to inhaled corticosteroid use outside the realm of randomized controlled trials.

METHODS: Different populations were examined cross-sectionally to determine whether self-reported use of inhaled corticosteroids was associated with control of asthma. Subjects with asthma in the community and those attending a university-based asthma program were studied. The definition of asthma control was based on the recommendations of the Canadian Consensus Report. The elements of asthma control were examined in the context of the subject's stated use and dose of the inhaled corticosteroid.

RESULTS: Asthma was controlled in $20 \%$ (95\% CI $18.7 \%$ to $21.3 \%$ ) of the 3427 subjects included in the present study. Only $15 \%$ (95\% CI $13.5 \%$ to $16.5 \%$ ) of the 2437 subjects using inhaled corticosteroids exhibited asthma control compared with 33\% (95\% CI $31.1 \%$ to $35.9 \%$ ) of the 990 subjects not using inhaled corticosteroids $(\mathrm{P}<0.000001)$.

CONCLUSIONS: Although it is known that inhaled corticosteroid therapy can result in asthma control in most individuals with asthma, the present study has shown that this result may not be attained outside the realm of randomized clinical trials. Inhaled corticosteroid use for asthma in a 'real world' setting appears to reflect disease severity.

\section{La corticothérapie en aérosol ne contrôle pas l'asthme}

HISTORIQUE : Des essais cliniques aléatoires démontrent l'efficacité de la corticothérapie en aérosol et indiquent que celle-ci peut contrôler l'asthme, mais on ne possède pas d'information détaillée sur la manière dont elle réalise cet objectif dans la collectivité.

OBJECTIFS : Déterminer si la corticothérapie en aérosol est efficace dans le contrôle de l'asthme et examiner les taux de contrôle de l'asthme reliés à l'usage de corticothérapie en aérosol hors du cadre d'essais aléatoires et contrôlés.

MÉTHODOLOGIE : Diverses populations ont fait l'objet d'analyses transversales pour établir si l'usage signalé par le patient d'une corticothérapie en aérosol s'associe au contrôle de l'asthme. Des sujets asthmatiques de la collectivité et des sujets participant à un programme contre l'asthme en milieu universitaire ont été étudiés. La définition de contrôle de l'asthme se fondait sur les recommandations du rapport consensuel canadien. Les éléments de contrôle de l'asthme ont été examinés d'après l'usage déclaré par les sujets et la dose de corticoïde en aérosol.

RÉSULTATS : L'asthme était contrôlé chez 20 \% (95 \% IC 18,7 \% à $21,3 \%$ ) des 3427 sujets participant à l'étude. Seulement $15 \%$ (95\% IC $13,5 \%$ à 16,5\%) des 2437 sujets sous corticothérapie en aérosol contrôlaient leur asthme, par rapport à 33 \% (95 \% IC 31,1 \% à 35,9\%) des 990 sujets qui n'utilisaient pas ce traitement $(\mathrm{P}<0,000001)$.

CONCLUSIONS : Bien qu'on sache que la corticothérapie en aérosol puisse assurer le contrôle de l'asthme chez la plupart des asthmatiques, la présente étude démontre que ce résultat n'est peut-être pas obtenu hors du cadre d'essais cliniques aléatoires. Le recours à la corticothérapie en aérosol contre l'asthme dans la "vraie vie » semble refléter la gravité de la maladie.

Key Words: Asthma control; Cross-sectional study; Inhaled corticosteroid; Severity

T here are two components to a prescription of medication for a chronic disease such as asthma. First, the need for such a prescription reflects the 'severity' of the disease. Second, the prescription is provided with the expectation that it will contribute to the 'control' of the disease. It is a well established fact that inhaled corticosteroid therapy is the backbone of treatment for asthma and should be used in all but the mildest forms of the disease (1). The efficacy of inhaled corticosteroids in asthma has been clearly demonstrated in a wide range of randomized controlled trials (1-3). Although it is known that lack of adherence with inhaled corticosteroid therapy is a major obstacle to its effectiveness, there have been very few studies examining the effect of these medications outside the realm of clinical trials. Population data, including analyses of mortality rates from asthma, have suggested that these drugs are effective in decreasing asthma mortality and probably morbidity (4-6). While these studies have given evidence that inhaled corticosteroid therapy improves asthma, there have been no data to show whether their use outside of clinical trials is associated with their demonstrated potential to control the disease. The control of asthma has been proposed by several asthma consensus guidelines (7-9) as the desirable outcome of treatment. In a study to determine whether asthma control was an achievable outcome, Bateman et al (10) concluded that overall control was achievable and that it should be regarded as the appropriate outcome for asthma studies. Not only is asthma control considered to have a major impact on the quality of life and productivity of those with the disease, but it may also have an important role in diminishing airway remodelling and subsequent fixed obstructive lung disease (11). Lack of disease

Calgary COPD and Asthma Program, University of Calgary, Calgary, Alberta

Correspondence and reprints: Dr Robert L Cowie, Health Sciences Centre, 3330 Hospital Drive Northwest, Calgary, Alberta T2N 4N1.

Telephone 403-220-8981, fax 403-270-8928, e-mail cowie@ucalgary.ca 


\section{TABLE 1}

\section{Definition of asthma control}

\section{Having none of the following characteristics}

Beta $_{2}$-agonist use to relieve symptoms > once per day

Waking at night with asthma in the past week

Emergency treatment for asthma in the past year

Missed work or school for asthma in past three months

control is associated with a substantial increase in the use of health care and direct, as well as indirect, costs of managing asthma (12-14).

In an initial sample examining the level of asthma control in a general population of subjects with current asthma, we noted that the proportion of patients with disease control was significantly lower for those reporting the use of inhaled corticosteroids. We subsequently examined three other groups of subjects with asthma to determine whether this was a consistent finding.

\section{METHODS}

The data used in the present study were obtained in a cross-sectional manner by interviewing subjects with asthma, using a questionnaire to determine the extent to which their asthma was controlled and the nature of the medications they used for asthma.

For the purpose of the present study, the definition of asthma control (Table 1) was based on the Canadian Asthma Consensus Guidelines which first presented a definition of asthma control in 1996 (8). Asthma control and current medication use were determined using a questionnaire that has been used in the authors' centre to assess over 3000 individuals with the disease. The data obtained from the questionnaire appear to correlate well with other findings related to asthma severity and control (15). The questions asked included the following direct questions about asthma control:

- Beta 2 -agonist use: "On average, how many doses of your bronchodilator (reliever medication) (Ventolin, Bricanyl, salbutamol, Berotec) do you use per day?"

- Waking at night: "In the past week, how many nights has your sleep been disturbed by asthma?"

- Emergency department visits: "Have you been to an emergency room or to a physician for urgent treatment of your asthma (for example, nebulized Ventolin) in the last 12 months?"

- Missed work/school: "Have you missed school or work because of asthma in the last three months?"

Additional questions were asked that were related to the patient's medication, including their use of inhaled and oral corticosteroids, asthma monitoring, use of action plans, hospital admissions and asthma trigger exposure.

The initial assessment was performed on data from a communitybased sample of subjects with current asthma. These subjects were recruited to complete a questionnaire when they attended a pharmacy to fill a prescription for asthma. Each subject was asked by the pharmacist and questionnaire whether they had physiciandiagnosed asthma. A total of 327 subjects indicated to the pharmacist that they had asthma, and of these, 301 subjects were 12 years of age or older and responded positively to the question
TABLE 2

Proportion of subjects with asthma with disease control in four separate populations in relation to their reported current use of inhaled corticosteroids (ICS)

\begin{tabular}{|c|c|c|c|}
\hline \multirow[b]{2}{*}{ Population } & \multicolumn{2}{|c|}{ Controlled } & \multirow[b]{2}{*}{$\mathbf{P}$} \\
\hline & On ICS, n (\%) & No ICS, n (\%) & \\
\hline Community study $(n=301)$ & $38(20)$ & $43(39)$ & 0.0004 \\
\hline Asthma clinic $(n=2686)$ & $246(13)$ & $229(30)$ & $<0.000001$ \\
\hline $\begin{array}{l}\text { Post asthma program group } \\
\qquad(\mathrm{n}=378)^{*}\end{array}$ & $72(27)$ & $53(50)$ & 0.00002 \\
\hline Adolescent study ( $n=62$ ) & $6(13)$ & $8(50)$ & 0.002 \\
\hline Total $(n=3427)$ & $362(15)$ & $333(33)$ & $<0.000001$ \\
\hline
\end{tabular}

*The post asthma program group as a whole had better asthma control (33\%) than the remainder of the subjects $(19 \%)(P<0.000001)$ suggesting that their educational intervention may have been effective

from the questionnaire asking if a physician had told them that they had asthma $(n=287)$ or wheezy bronchitis $(n=14)$. The findings of this community-based sample were then compared with the findings from three other groups of subjects with asthma. The first of these additional groups consisted of 2686 subjects with asthma who were assessed when they first attended a universitybased asthma program. The second group was comprised of a subset of 378 of these subjects who were reassessed one year after completing an asthma education program. The third group consisted of 62 adolescent subjects with asthma assessed six months after attending an age-specific asthma education program. In each of these groups, inhaled steroid use and their reported asthma control were based on self-report. In the group of subjects attending the university-based asthma program, measurements of lung function were made at the time they completed their questionnaires to serve as an objective indication of their asthma severity.

Each element of the definition of asthma control and whether control was achieved were assessed in relation to self-reported inhaled corticosteroid use. The data were analyzed by $\chi^{2}$ for dichotomous data, and by Student's $t$ test for continuous data using EpiInfo version 6 (Centers for Disease Control and Prevention, USA). EpiInfo was also used for the calculation of odds ratios and 95\% CIs.

\section{RESULTS}

A significant difference in asthma control was noted in each of the four groups of subjects when comparing subjects reporting the use of inhaled corticosteroids with those not reporting the use of these medications. In each instance, the proportion of subjects with asthma control was higher in the group not using inhaled corticosteroids (Table 2). When combining the 3427 subjects from the four groups, 695 (20\%) reported asthma control using the criteria defined in the present study. Disease control was apparent in 362 of the 2418 subjects $(15 \%, 95 \% \mathrm{CI}$ $13.5 \%$ to $16.5 \%$ ) reporting inhaled corticosteroid use and 333 of 1009 subjects $(33 \%, 95 \%$ CI $31.1 \%$ to $35.9 \%$ ) reporting no inhaled corticosteroid use. The difference between the two groups was significant $(18 \%$, 95\% CI $14.7 \%$ to $21.3 \%$; $\mathrm{P}<0.00001)$, with an odds ratio for uncontrolled asthma of 2.8 (95\% CI 2.35 to 3.34) for subjects reporting inhaled corticosteroid use. The proportion of subjects with disease control was inversely related to the dose of inhaled corticosteroid used: asthma was controlled in $33 \%$ of those on no inhaled corticosteroids, $21 \%$ of those taking $500 \mu \mathrm{g} /$ day or less (beclomethasone dipropionate equivalent), $16 \%$ of those taking between $501 \mu \mathrm{g} /$ day and $1000 \mu \mathrm{g} /$ day, and $7 \%$ of those using more than $1000 \mu \mathrm{g} /$ day $(\mathrm{P}<0.000001)$ (Figure 1). When comparing the 


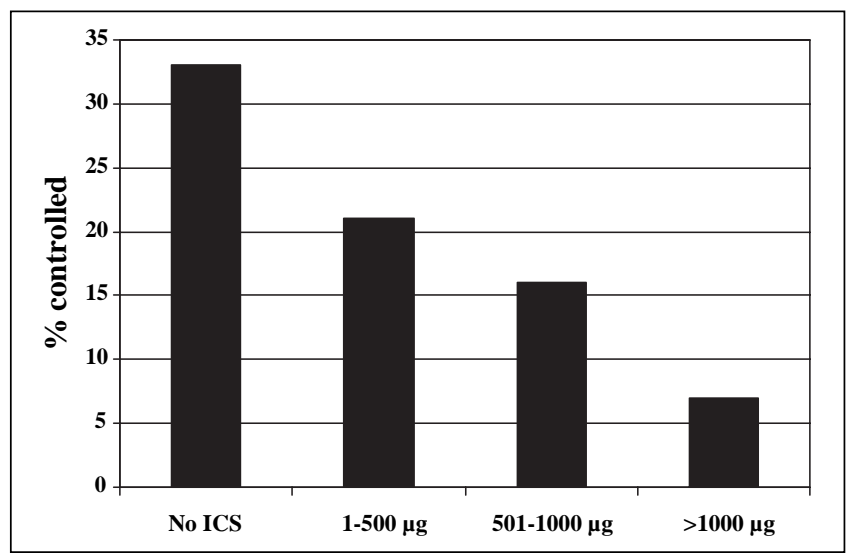

Figure 1) Percentage of subjects demonstrating asthma control by category of inhaled corticosteroid (ICS) therapy using beclomethasone dipropionate equivalent doses $(P<0.000001)$

individual elements of the definition of control, there were significant differences in each of these elements in relation to inhaled corticosteroid use (Table 3). The differences were

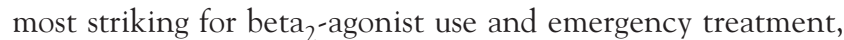
and less so for nighttime waking and time off from work or school. In the subjects attending the asthma program, lung function measurements showed a small, but statistically significant, difference in forced expiratory volume in $1 \mathrm{~s}$ and forced expiratory volume in $1 \mathrm{~s}$ to forced vital capacity percentage in favour of the subjects reporting no current inhaled corticosteroid use (Table 4).

Analysis of other subject characteristics, on the basis of whether they reported use of inhaled corticosteroids, revealed a small but statistically significant difference with age. Subjects who used inhaled corticosteroids were older (mean \pm SD; $41.5 \pm 16.68$ years) than those who did not use inhaled corticosteroids $(38.9 \pm 15.90$ years $)(P=0.002)$. Among the four groups, only the adolescent group, who had been selected from a very small age range, did not display any difference for age on the basis of their inhaled corticosteroid use. The proportion of female subjects was higher among inhaled corticosteroid users $(65 \%)$ than among those who did not use inhaled corticosteroids (59\%) $(\mathrm{P}=0.002)$. The mean daily use of beta 2 -agonists was higher in the inhaled corticosteroid users (mean $\pm \mathrm{SD}$; $3.9 \pm 4.34$ ) than the nonusers $(2.4 \pm 3.69),(P=0.000001)$. Hospital admissions in the past year were reported by $20 \%$ of the inhaled corticosteroid users and by $8 \%$ of the nonusers $(\mathrm{P}=0.000001)$. The two groups did not differ with regard to smoking or having household animals.

\section{DISCUSSION}

In the present cross-sectional study, we noted a consistently smaller proportion of subjects with asthma control in those reporting the use of inhaled corticosteroids. There are ample data to demonstrate the efficacy of inhaled corticosteroid therapy in the control of asthma, and it is, thus, improbable that our observation suggests an adverse effect from these medications. However, it is probable that the use of inhaled corticosteroids in the populations studied was an indication of disease severity. Similar findings have been recorded by others (16-18) and have been explained by suggesting that inhaled corticosteroid use reflects disease severity. It might be expected that subjects with
TABLE 3

Indicators of poor asthma control in relation to reported current use of inhaled corticosteroids (ICS) for asthma in 3427 subjects with asthma

\begin{tabular}{lccc}
\hline $\begin{array}{l}\text { Indicator of poor } \\
\text { asthma control }\end{array}$ & On ICS, n (\%) & No ICS, n (\%) & P \\
\hline $\begin{array}{l}\text { Use beta } \text {-agonists > once per day } \\
\text { Wake at night in past week }\end{array}$ & $1561(65)$ & $409(41)$ & $<0.000001$ \\
$\begin{array}{l}\text { Emergency treatment for } \\
\quad \text { asthma in past year }\end{array}$ & $1090(45)$ & $298(30)$ & $<0.000001$ \\
$\begin{array}{l}\text { Missed work/school in } \\
\text { past three months }\end{array}$ & $238(10)$ & $77(8)$ & 0.04 \\
\hline
\end{tabular}

TABLE 4

Spirometry in relation to reported current use of inhaled corticosterioids (ICS) for asthma*

\begin{tabular}{lccc}
\hline & $\begin{array}{c}\text { On ICS }(\mathbf{n}=1750) \\
\text { Mean (SD) }\end{array}$ & $\begin{array}{c}\text { No ICS }(\mathbf{n}=\mathbf{7 5 0}) \\
\text { Mean (SD) }\end{array}$ & P \\
\hline FVC $(\%)^{\dagger}$ & $91(18.9)$ & $93(17.9)$ & 0.08 \\
$\mathrm{FEV}_{1}(\%)^{\ddagger}$ & $78(22.5)$ & $82(21.3)$ & $<0.0001$ \\
$\mathrm{FEV}_{1} / \mathrm{FVC}(\%)$ & $70(13.1)$ & $73(12.3)$ & $<0.000001$
\end{tabular}

*Data are based on studies from 2500 of the 2686 subjects attending an asthma program for whom spirometry information was available; tThe forced vital capacity (FVC) expressed as a percentage of predicted (24); ¥The forced expiratory volume in $1 \mathrm{~s}\left(F E V_{1}\right)$ expressed as a percentage of predicted (24). $F E V_{1} / F V C=\left(F E V_{1} \times 100\right) / F V C$

more severe asthma would have more of the features that define a lack of asthma control. However, the purpose of medication prescription in asthma is to achieve disease control, and Cockroft (16) has stated that, "With appropriate therapy, many of these defining features (clinical features of asthma) should be minimal or absent". He further states that the goal of asthma control is readily achievable and that it should be the same for all degrees of asthma severity; in this context, our study shows that this objective is not widely achieved. Vollmer et al (13) stated that asthma control is the net result of severity, medical management and patient adherence. In a perfect world, only the level of therapy would indicate severity (17). Bateman et al (10) showed that asthma control was an achievable end point in a clinical trial setting. It does not seem unreasonable to believe that this outcome should be generalizable to everyday practice (16). In choosing a definition of disease control, we used the Canadian Asthma Guidelines, but chose a slightly less strict definition of control (Table 1) with regard to the use of beta ${ }_{2}$-agonists. The nature of our questionnaire was such that it was difficult to estimate the use of beta 2 agonists/week. Therefore, we chose to define poor control in the context of beta ${ }_{2}$-agonist use as the need to use these medications to relieve symptoms more than once/day, a less strict definition than that of more than three times/week suggested by the guidelines (8). Similar definitions of asthma control have been used in other studies $(13,18)$.

The weakness of our study lies in its cross-sectional design. For example, it is possible that a subject had started to use inhaled corticosteroids after a visit to the emergency department or after a period of missed work or school, and that episode or event would, thus, be wrongly attributed to or associated with their use of these medications. With that concern in mind, we recalculated the data using only beta 2 -agonist use of more than once/day and night waking with asthma in the previous week 
as indicators of poor current control. The difference in the proportion of subjects who conformed with this new definition of asthma control remained significantly different, with $24 \%$ of the inhaled corticosteroid users and $42 \%$ of the nonusers demonstrating disease control $(\mathrm{P}<0.000001)$.

Using four different populations of subjects with asthma, we demonstrated a consistent pattern of less effective disease control in those reporting current inhaled corticosteroid use. These findings support a conclusion that inhaled corticosteroid use is more common in those who have more severe asthma. Our data do not show, nor do we suggest, that these medications fail to improve asthma control. The proportion of patients not achieving asthma control might be greater and the markers of poorly controlled asthma could be worse were these subjects not receiving inhaled corticosteroid therapy. Data from the large body of efficacy studies (randomized clinical trials) and the few other noninterventional studies support the view that these medications can and do improve asthma control $(1,4,5,10)$. However, our study has shown that, in reality, inhaled corticosteroids are not used by those with asthma to achieve disease control, the proposed end point of treatment.

Efficacy studies, of which the randomized clinical trial is the standard format, are an essential component for determining whether a new treatment modality can work. They do not, however, always identify whether the new treatment will work (be effective) in a 'real world' situation. The reasons that an efficacious treatment fails to achieve its promised success are largely related to issues of adherence (19). Subjects may not use their therapy in the manner in which it was prescribed (20) or

\section{REFERENCES}

1. Barnes PJ, Pedersen S. Efficacy and safety of inhaled corticosteroids in asthma. Report of a workshop held in Eze, France, October 1992. Am Rev Respir Dis 1993;148:S1-S26.

2. Haahtela T, Jarvinen M, Kava T, et al. Comparison of a beta ${ }_{2}$-agonist, terbutaline, with an inhaled corticosteroid, budesonide, in newly detected asthma. N Engl J Med 1991;325:388-92.

3. Juniper EF, Kline PA, Vanzieleghem MA, Ramsdale EH, O'Byrne PM, Hargreave FE. Effect of long-term treatment with an inhaled corticosteroid (budesonide) on airway hyperresponsiveness and clinical asthma in nonsteroid-dependent asthmatics. Am Rev Respir Dis 1990;142:832-6.

4. Ernst P, Spitzer WO, Suissa S, et al. Risk of fatal and near-fatal asthma in relation to inhaled corticosteroid use. JAMA 1992;268:3462-4.

5. Suissa S, Ernst P, Benayoun S, Baltzan M, Cai B. Low-dose inhaled corticosteroids and the prevention of death from asthma. N Engl J Med 2000;343:332-6.

6. Anis AH, Lynd LD, Wang XH, et al. Double trouble: Impact of inappropriate use of asthma medication on the use of health care resources. CMAJ 2001;164:625-31.

7. National Heart Lung and Blood Institute. Expert Panel Report 2: Guidelines for the diagnosis and management of asthma. Bethesda: National Institutes of Health, 1997.

8. Ernst P, FitzGerald JM, Spier S. Canadian Asthma Consensus Conference: Summary of recommendations. Can Respir J 1996;3:89-100.

9. British Thoracic Society, National Asthma Campaign, Royal College of Physicians of London in association with the General Practioner in Asthma Group, et al. The British guidelines on asthma management 1995. Review and position statement. Thorax 1997;52:S1-S21.

10. Bateman ED, Bousquet J, Braunstein GL. Is overall asthma control being achieved? A hypothesis-generating study. Eur Respir J 2001;17:589-95.

11. Boulet LP. Asthma therapy: Effects on airway inflammation and remodelling. Can Respir J 1998;5:68-70.

12. Ungar WJ, Coyte PC, Chapman KR, MacKeigan L. The patient level cost of asthma in adults in south central Ontario. Pharmacy may not be using their inhaler devices correctly (21). Physicians are also often guilty of poor adherence when they prescribe the treatment incorrectly, either by giving incorrect doses or dose frequencies, by giving incomplete information about the treatment or failing to provide appropriate companion interventions $(22,23)$. A second major reason for the discrepancy between the efficacy (randomized clinical trials) and the effect of an intervention is that randomized clinical trials inflate the expectations for a new treatment because of their tendency to occur in synthetic environments and the use highly selected subjects.

In the present study, we have demonstrated a previously noted overall lack of disease control in populations with asthma (23). In addition, the present study has demonstrated that disease control is present less often in subjects with asthma who report the use of inhaled corticosteroids. This finding was confirmed in samples from four different populations of subjects with asthma.

\section{CONCLUSION}

Inhaled corticosteroid use generally reflects the severity of asthma, and often does not achieve its stated and intended purpose of disease control. Thus, it is likely that patient education (see Table 2) and other nonpharmacological interventions are required to achieve the expected benefit from a prescription of inhaled corticosteroids in the management of asthma.

FUNDING: The study was funded by the Calgary COPD and Asthma Program.

Medication Monitoring Program Advisory Board. Can Respir J 1998;5:463-71.

13. Vollmer WM, Markson LE, O'Connor E, et al. Association of asthma control with health care utilization and quality of life. Am J Respir Crit Care Med 1999;160:1647-52.

14. Vollmer WM, Markson LE, O'Connor E, Frazier EA, Berger M, Buist AS. Association of asthma control with health care utilization: A prospective evaluation. Am J Respir Crit Care Med 2002;165:195-9.

15. Cowie RL, Underwood MF, Revitt SG, Field SK. Predicting emergency room utilization in adults with asthma: A cohort study. J Asthma 2001;38:179-84.

16. Cockcroft DW, Swystun VA. Asthma control versus asthma severity. J Allergy Clin Immunol 1996;98:1016-8.

17. Ungar WJ, Chapman KR, Santos MT. Assessment of a medicationbased asthma index for population research. Am J Respir Crit Care Med 2002;165:190-4.

18. Unwin D, Jones K, Hargreaves C, Gray J, for the Eden Valley General Practice Research Group. Using a revised asthma morbidity index to identify varying patterns of morbidity in UK general practices. Respir Med 2001;95:1006-11.

19. Legorreta AP, Christian-Herman J, O'Connor RD, Hasan MM, Evans R, Leung KM. Compliance with national asthma management guidelines and specialty care: A health maintenance organization experience. Arch Intern Med 1998;158:457-64.

20. Milgrom H, Bender B, Ackerson L, Bowry P, Smith H, Rand C. Noncompliance and treatment failure in children with asthma. J Allergy Clin Immunol 1996;98:1051-7.

21. Giraud V, Roche N. Misuse of corticosteroid metered-dose inhaler is associated with decreased asthma stability. Eur Respir J 2002;19:246-51.

22. Boulet LP. Perception of the role and potential side effects of inhaled corticosteroids among asthmatic patients. Chest 1998;113:587-92.

23. Chapman KR, Ernst P, Grenville A, Dewland P, Zimmerman S. Control of asthma in Canada: Failure to achieve guideline targets. Can Respir J 2001;8(Suppl A):35A-40A.

24. Crapo R, Morris AH, Gardner RM. Reference spirometric values using techniques and equipment that meet ATS recommendations. Am Rev Respir Dis 1981;123:659-64. 


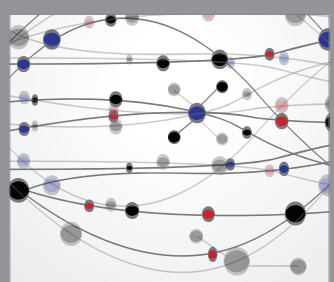

The Scientific World Journal
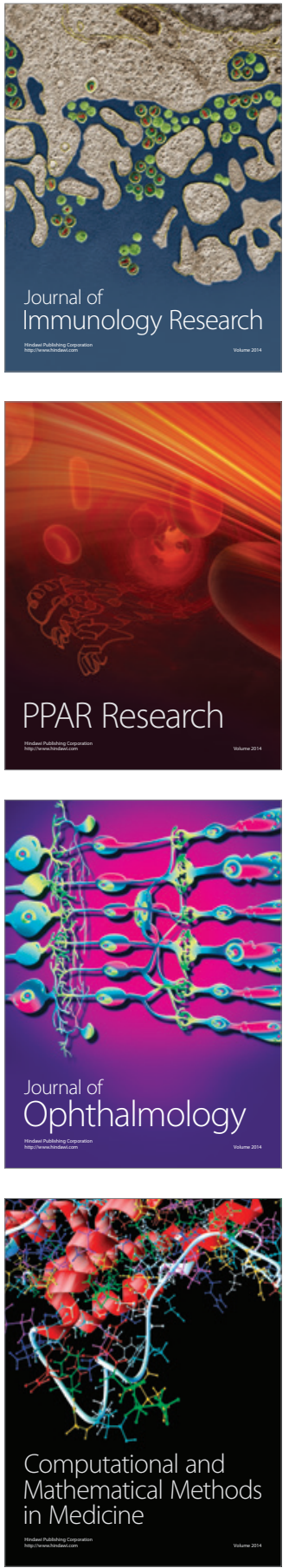

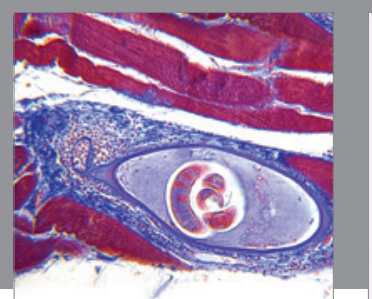

Gastroenterology Research and Practice

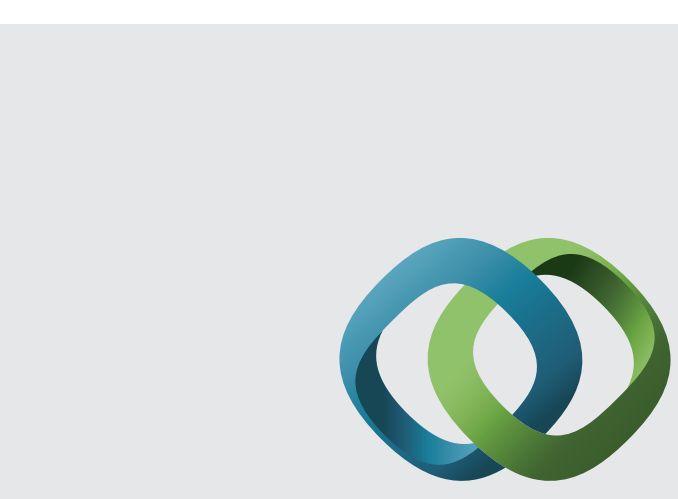

\section{Hindawi}

Submit your manuscripts at

http://www.hindawi.com
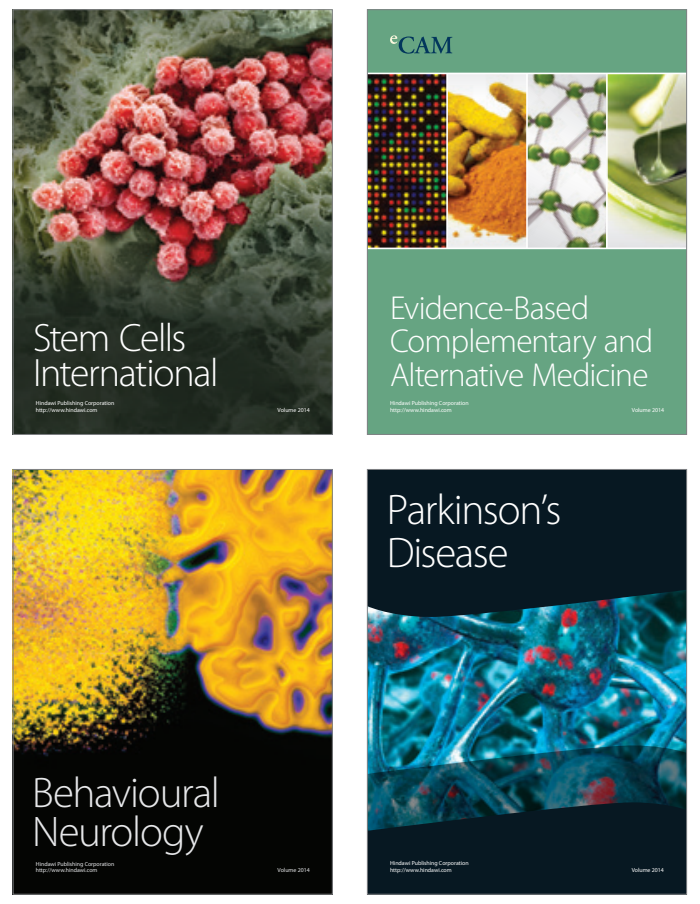
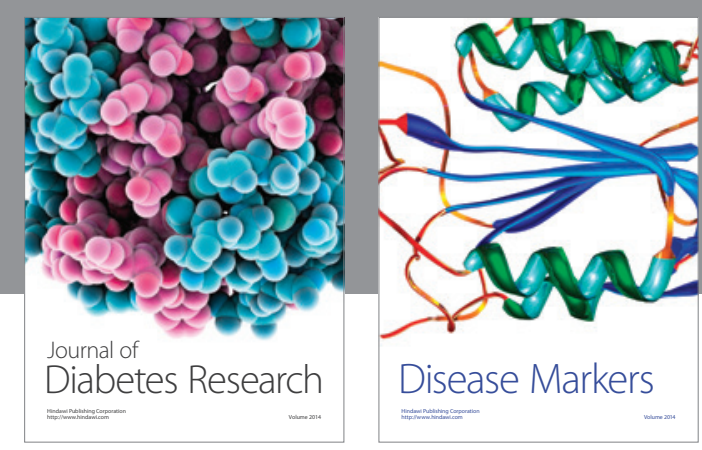

Disease Markers
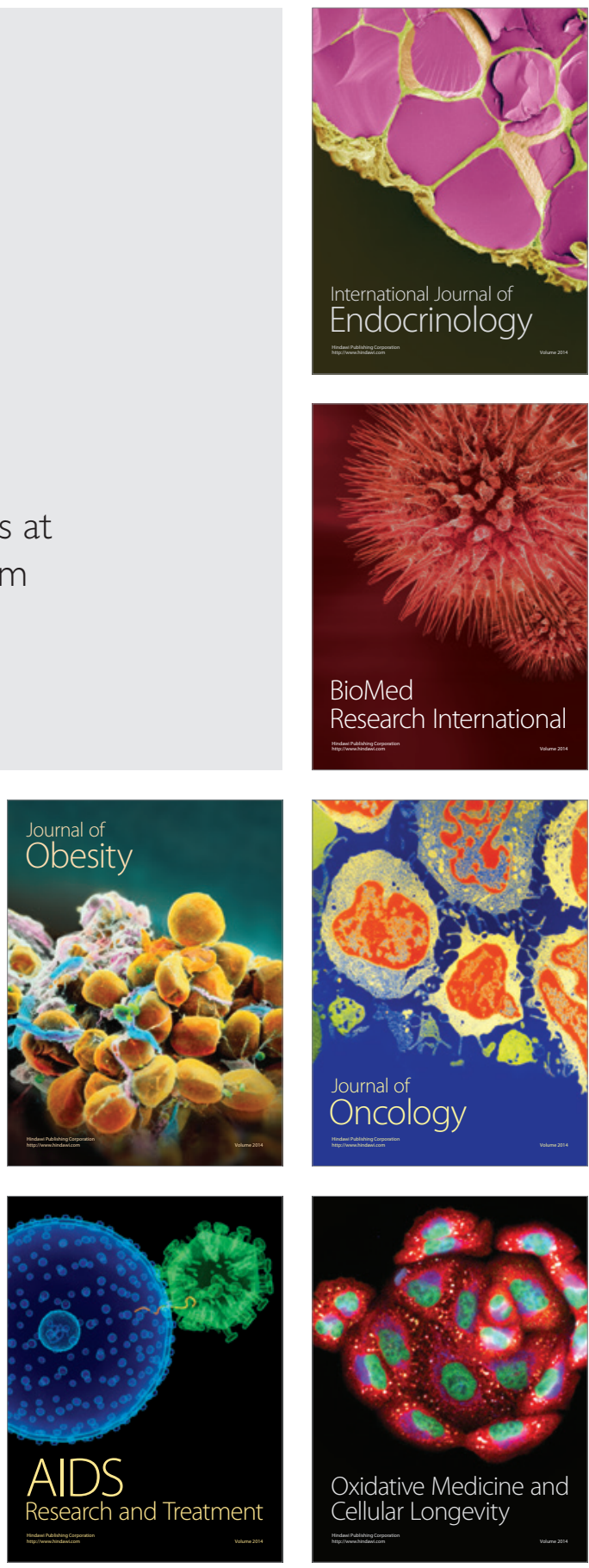